\title{
Response pretraining and forced availability in paired-associate verbal learning'
}

\author{
Willard N. Runquist, UNIVERSITY OF ALBERTA \\ Judith M. English, POMONA COLLEGE
}

\begin{abstract}
Abstraet
Facilitation by relevant response pretraining was obtained when responses were made available by the Saltz card study technique, but only if a fixed search time was used. Irrelevant response pretraining produced facilitation when the search time was not limited, suggesting that Saltz's procedure does not simply force availability.
\end{abstract}

Problem

This study is a partial replication and extension of a study reported by Saltz (1961) in which the effects of response pretraining were demonstrated in a pairedassociate task where response availability presumably was not a factor.

The validity of this conclusion, however, depends upon the validity of the procedure used to eliminate the effects of availability. Saltz's procedure was to provide cards containing the response terms, so that all response terms were immediately available. In order to force Ss to use the cards, Saltz had the Ss locate the correct response and give its serial position on the card.

There is a possibility, however, that the procedure used by Saltz did not allow the S sufficient time so that, unless the response terms were already available, he was unable to use the cards at all in the allotted time. Hence, response availability still could be producing facilitation with pretraining.

An attempt was made to rectify this possible shortcoming of Saltz's study by the simple expedient of extending the time interval allowed for response. If our interpretation of Saltz's findings is correct, facilitation due to response pretraining will not appear with this longer time allowance.

\section{Method}

Fifteen volunteer students served as Ss in each of four groups. Two of the groups received five trials of free recall learning of the ten adjectives to be used as response terms, while two groups received the same training on a list of irrelevant adjectives. On each trial the adjectives were presented singly for $2 \mathrm{sec}$. each followed by a written recall test.

Each group then learned to pair the relevant adjectives with ten low similarity, low association value trigrams. One relevant (R-P) and one irrelevant (I-P) trained group learned the list under paced conditions, i. e., a 4:2 presentation rate, while the remaining two groups, a relevant trained (R-U) and an irrelevant trained (I-U), learned under an S-paced condition in which the anticipation interval was as long as $\mathrm{S}$ needed, and the study interval 2 sec. Saltz's technique was used in both con- ditions. Each S received a stack of cards each containing all of the response terms but in a different order on each card. Instead of giving the response term, $\mathrm{S}$ was required to give the serial position of the response term on that card. During a 6-sec. intertrial interval, $\mathrm{S}$ shifted to a different card, so that he could not learn the serial order. Thus, in the paced groups, he was allowed $4 \mathrm{sec}$. to give a response, while in the unpaced groups he was given an unlimited time to respond, with the correct response term being shown immediately following the S's response.

All learning materials were presented with a filmstrip projector. Sixteen trials were given unless $\mathrm{S}$ made two consecutive errorless trials, in which case he was dismissed and his data scored correct for remaining trials.

\section{Results}

Performance during the paired-associate phase of the experiment is shown in Fig. 1 in terms of per cent correct responses on each trial. All Ss reached criterion in the unpaced conditions by the twelfth trial so the performance is not shown beyond that point. The results for the paced groups are similar to those obtained by Saltz (1961) and show some evidence of facilitation due to response pretraining in the earlytrials. There is also evidence of poorer performance in later trials, however. A totally unexpected finding is the superiority of the

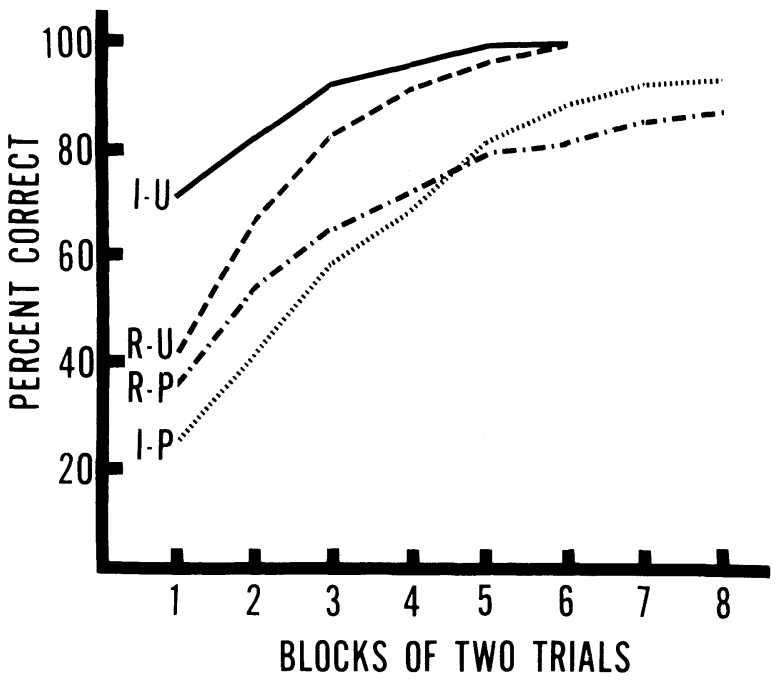

Fig. 1. Paired-associate performance under paced (P) and unpaced (U) conditions following relevant (R) and irrelevant (I) response learning. 
irrelevant response learning control group when the task is S-paced. Since the availability hypothesis predicts facilitation only in early trials, analysis of variance was performed on the total correct responses over the first seven trials. Significant values of $F$ were obtained for paced vs. unpaced presentation, and for the interaction between response pretraining and pacing conditions $[F(1,56)=30.01$ and 7.40 respectively, error m. s. 179.19] . Separate t-tests comparing the relevant and irrelevant response learning conditions within each pacing condition resulted in a significant difference between the unpaced groups, $t(56)=2.42$, while the paced groups did not differ significantly unless one assumes a one-tailed alternative, $t(56)=1.75$.

A separate trend analysis of the paced conditions revealed a significant difference in linear trend for the two groups $[\mathrm{F}(1,28)=9.52]$. Although this finding does not definitively attest to the reliability of the interaction with trials, it does tend to support this interpretation.

Further analysis gives credence to a conclusion that some facilitation did occur in the paced condition. For each S total performance during paired-associate learning was determined for the five items given correctly the most times and for the items given correctly the fewest times during the response recall pretraining. In the paced groups, 9 of the 15 Ss showed superiority on the "more available" items, with a mean difference of 2.6 correct responses being obtained on the two kinds of items. For the unpaced Ss only five Ss showed better performance on the more available items although there was a mean difference of .6 correct responses favoring these items.

\section{Discussion}

Although there are some aspects of these findings which are puzzling, one thing is quite clear. No facili- tation due to relevant response pretraining appeared in the unpaced conditions and, indeed, very little appeared in the paced conditions. We do not mean to imply, however, that these findings demonstrate the inadequacy of Saltz's hypothesis. Only further research can clarify the issues Saltz raises. However, the results of this study do indicate the inappropriateness of the card study method for controlling availability. Just what this procedure does entail psychologically is not clear. Neither the availability hypothesis (Underwood et al., 1959) nor Saltz's differentiation hypothesis can satisfactorily account for the results of the unpaced group. It does appear that the card study procedure has much more complicated psychological effects than simply forcing availability of response terms. As it has been pointed out elsewhere (Schulz \& Lovelace, 1964), procedures which simply control availability may be difficult to establish.

\section{References}

SALTZ, E. Response pretraining: Differentiation or availability? J.exp. Psychol., 1961, 62, 583-587.

SCHULZ, R. W., \& LOVELACE, E. A. Meaningfulness and the associative phase of paired-associate learning: A methodological consideration. Psychon. Sci., 1964, 1, 37-38.

UNDERWOOD, B. J., RUNDQUIST, W. N., \& SCHULZ, R. W. Response learning in paired-associate lists as a function of intralist similarity. J.exp. Psychol., $1959,58,70-78$.

\section{Note}

1. The junior author was a participant in the National Science Foundation Undergraduate Research Participation Program at Pomona College where these data were collected. 